\title{
Preliminary Clinical Evaluation of Short Fiber-Reinforced Composite Resin in Posterior Teeth: 12-Months Report
}

\author{
Garoushi $\mathrm{S}^{1,2, *}$, Tanner $\mathrm{J}^{2,3}$, Vallittu $\mathrm{PK}^{1,2}$ and Lassila $\mathrm{L}^{1,2}$ \\ ${ }^{I}$ Department of Biomaterials Science, Institute of Dentistry, University of Turku, Turku, Finland \\ ${ }^{2}$ BioCity Turku Biomaterials Research Program and Turku Clinical Biomaterials Centre - TCBC, Finland \\ ${ }^{3}$ Department of Prosthetic Dentistry, Institute of Dentistry, University of Turku, Turku, Finland
}

\begin{abstract}
This preliminary clinical trial evaluated 12 month clinical performance of novel filling composite resin system which combines short fiber-reinforced composite resin and conventional particulate filler composite resin in high stress bearing applications. A total of 37 class I and II restorations (compound and complex type) were placed in 6 premolars and 31 molars. The restorations were reviewed clinically at 6 months (baseline) and 12 months using modified USPHS codes change criteria for marginal adaptation, post-operative sensitivity, pulpal pain and secondary caries criteria. Photographs and $\mathrm{x}$-rays were obtained for restorative analysis. Results of 12 months evaluation showed 5 restorations having little marginal leakage (B score) and 1 patient had minor pulpal symptom and post-operative sensitivity (B score). No secondary caries or bulk fracture was detected. The majority of restorations exhibited A scores of the evaluated criteria. After 12 months, restorations combining base of short fiber reinforced composite resin as substructure and surface layer of hybrid composite resin displayed promising performance in high load bearing areas.
\end{abstract}

Keywords: Short fiber reinforced composite, clinical trial, posterior restoration.

\section{INTRODUCTION}

Dental restorative filling composite resins have been introduced to dental community in 1960's [1]. Since then after many significant material improvements restorative composite still suffers lack of mechanical properties and problems related to polymerization shrinkage. Clinical studies have shown that direct fillings fail predominantly because of occlusal wear or secondary caries [2-5]. However, fracture of restorative composite is reported also as a common reason for replacement [3,5]. Due the failures of this kind, it is still controversial, whether restorative composites should be used in large high-stress bearing applications such as in direct posterior restorations $[4,5]$. The relatively high brittleness and low fracture toughness of current composites still hinder their use in these large stress-bearing restorations [6-8].

Studies have been undertaken to evaluate and improve restorative composite resin against wear and lower the polymerization shrinkage. Attempts have been made to change type of filler or filler size and their silanization, by changing the polymerization kinetics of resins and to influence to degreeof monomer conversion [9-12]. Reinforcing the resin with glass fibers $[13,14]$, with fiber-reinforced composite (FRC) substructure [15,16], whiskers [17], particulate ceramic fillers (dense and porous) [18] and optimization of filler content [9] are among the methods that have been studied. Some other aspect relating to indirect laboratory made composites have been investigated by using post-curing to enhance composite strength and toughness [19].

*Address correspondence to this author at the Department of Biomaterials Science Institute of Dentistry and BioCity Turku Biomaterials Research Program University of Turku Turku, Finland; Tel: + 358 504063976;

Fax: +358 233383 90; E-mail: sufgar@utu.fi
Recently, short fiber reinforced composite was introduced as a dental restorative composite resin [20-23]. The composite resin is intended to be used in high stress bearing areas especially in molars. The results of the laboratory mechanical tests revealed substantial improvements in the load bearing capacity, the flexural strength and fracture toughness of dental composite resin reinforced with short E-glass fiber fillers in comparison with conventional particulate filler restorative composite resin [20-23]. The short fiber composite resin has also revealed control of the polymerization shrinkage stress by fiber orientation and, thus, marginal microleakage was reduced compared with conventional particulate filler restorative composite resins [22].

Based on the published and our unpublished results of the physical properties of short fiber reinforced composite, it is suggested that short fiber composite resin could be used to fulfill the requirements for the ideal posterior restorations. The short fiber composite is intended to be used as bulk substructure material which will be covered by a layer of particulate filler composite. It is difficult to predict clinical long-term performance from only laboratory experiments. Thus, the aim was to conduct a pilot clinical trial investigating the performance of materials combination of bulk short fiber reinforced composite substructure and surface particulate filler composite in high stress bearing applications.

\section{MATERIALS AND METHODS}

\section{Patients' Selection and Restorative Procedure}

The methods used in this investigation have been widely reported $[24,25]$ and was approved by the Joint Commission on Ethics of the Turku University and the Turku University Hospital (20.6.2006). For this study, the case reports of 35 
Table 1. Characteristics of Patients and Restorations

\begin{tabular}{|c|c|}
\hline & 12 Months \\
\hline \hline Mean age \pm SD & $42 \pm 15$ \\
\hline Females & 14 \\
\hline Males & 21 \\
\hline Restorations & 37 \\
\hline Premolars & 6 \\
\hline Molars & 31 \\
\hline Mean number of surface per restoration & $2.9 \pm 1.2$ \\
New restorations & 10 \\
Replacement of old restorations & 27 \\
\hline
\end{tabular}

adult patients were selected according to pre-determined inclusion criteria among the registers of private practice dental offices in Finland from January 2009 to May 2011. All teeth were in occlusion and had at least one proximal contact with an adjacent tooth. Patients with extremely poor oral hygiene, heavy bruxism habits or periodontal problems were excluded.

Restorative procedures were carried out by many dentists. Before the start of the study, the operative procedure was thoroughly discussed with the dentists. 31 (84\%) of restorations were placed in molars and $6(16 \%)$ in premolar. The majority of the restorations were of a complex type with more than 2 surfaces included. Reason for restorations in $31 \%$ of patients was the presence of caries, in $29 \%$ of patients the replacement of old restorations and $40 \%$ of patients restorations after endodontic treatments (Table 1). Concerning the method of isolation, the use of rubber dam or simply cotton rolls and aspiration, was determined according to a predetermine scheme of randomization.

Three different adhesive systems were used randomly. Single-step self etch primer and bond (Vivapen, IvoclarVivadent, Schaan, Liechtenstein) and two-steps self etch primer and bond (Clearfil SE bond, Kuraray, Tokyo, Japan) and three-steps etching, primer and bond (Scotchbond multipurpose adhesive, 3M ESPE, USA). Bonding agents were

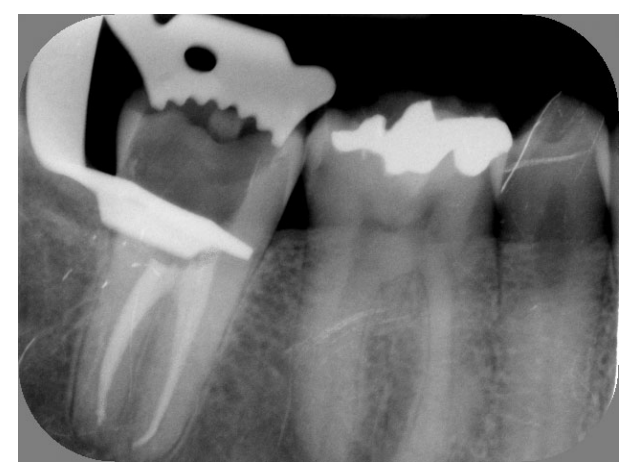

Fig. (1). Lower right second molar has been root canal treated. Gutta percha up to $3 \mathrm{~mm}$ is removed from the canal orifices.

placed according to manufacturer's instructions. Flow composite resin was applied on the bottom of $84 \%$ of cavities prior placing the short fiber reinforced composite (Xenious, StickTeck Ltd, Turku, Finland). The short fiber composite resin was placed and light-cured according to an incremental technique. All restorations were fully covered with a one layer (1-2 $\mathrm{mm})$ of hybrid composite resins [(Estelite, Tokuyama, Japan), (Clearfil Majesty Posterior,Kuraray, Japan), (Z250 and Z100 3MESPE, USA), (Synergy, Coltène/Whaledent, Altstätten, Switzerland)] then occlusion was carefully adjusted with articulating paper. Finishing and polishing procedures were carried at same visit after occlusal adjustment.

\section{Evaluation}

The restorations were evaluated after 6 months (baseline) and 12 months by same operator. Each restoration was evaluated according to slightly modified USPHS criteria for the following characteristics: marginal adaptation, postoperative sensitivity, pulpal pain and secondary caries [24, 25] (Table 2). Photograph and X-ray records of restorations were used (Fig. 1-5).

\section{RESULTS AND DISCUSSION}

Results of 12 months evaluation showed 5 restorations having little marginal leakage (B score) and 1 patient had minor pulpal symptom and post-operative sensitivity (B

Table 2. Modified USPHS Criteria Used

\begin{tabular}{|c|c|c|}
\hline Criteria & Code & Definition \\
\hline \multirow[t]{3}{*}{ marginal adaptation } & A & $\begin{array}{l}\text { Restoration closely adapted to the tooth, No explorer catch at margins, or there was a catch } \\
\text { in one direction }\end{array}$ \\
\hline & B & $\begin{array}{l}\text { Explorer catch. No visible evidence of a crevice into which explorer could penetrate. No } \\
\text { dentin or base visible }\end{array}$ \\
\hline & $\mathrm{C}$ & Explorer penetrates into a crevice that is of a depth that expose dentin or base \\
\hline post operative sensitivity & $\begin{array}{l}\text { A } \\
\text { B } \\
\text { C } \\
\text { D }\end{array}$ & $\begin{array}{l}\text { None } \\
\text { Mild but bearable } \\
\text { Uncomfortable, but no replacement is necessary } \\
\text { Painful. Replacement of restoration is necessary }\end{array}$ \\
\hline pulpal symptoms & $\begin{array}{l}\text { A } \\
\text { B } \\
\text { C } \\
\text { D }\end{array}$ & $\begin{array}{l}\text { No symptoms } \\
\text { Minor symptoms } \\
\text { Major symptoms } \\
\text { Extensive symptoms }\end{array}$ \\
\hline secondary caries & $\begin{array}{l}\text { A } \\
\text { B }\end{array}$ & $\begin{array}{l}\text { Absent } \\
\text { Present }\end{array}$ \\
\hline
\end{tabular}




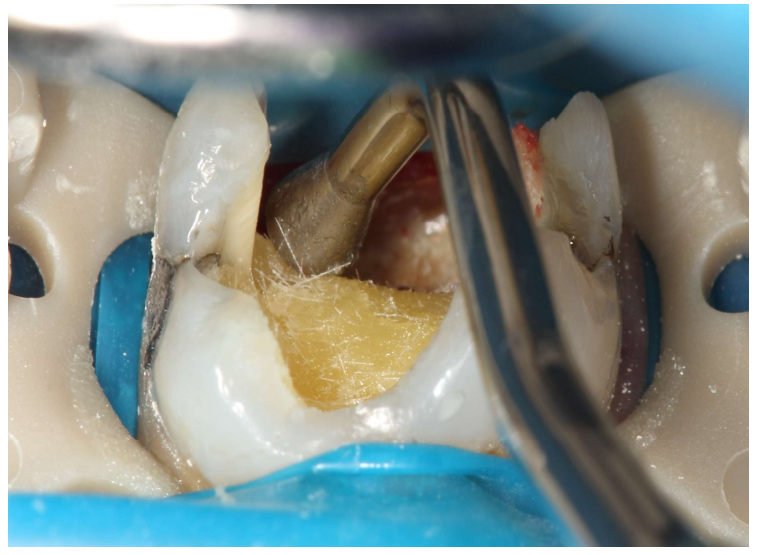

Fig. (2). Placement of bulk short fiber composite according to an incremental technique

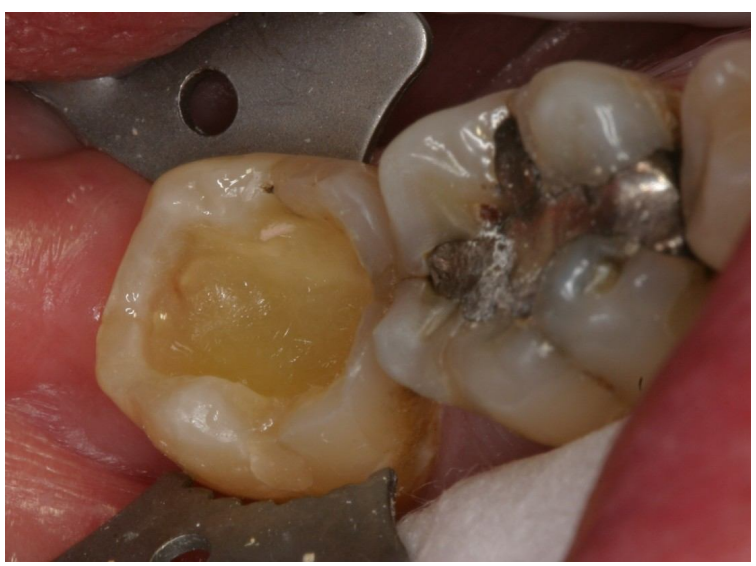

Fig. (3). Dentin and enamel surfaces are bonded and bulk short fiber composite substructure applied and light cured in three layers.

score). No secondary caries or bulk fracture have been detected. The majority of restorations exhibited A scores of the evaluated criteria.

These results of short-term pilot clinical reports were according to the expectations, since several in vitro studies have already shown a satisfactory performance of using same materials combination in different high stress bearing applications [20-23,26-28].

The function of bulk short fiber composite substructure is based on supporting the surface particulate filler composite layer and working as crack stopper layer. Reinforcing effect of the fiber fillers is based on stress transfer from polymer matrix to fibers but also behavior of individual fiber as a crack stopper. Random fiber orientation had a significant role in mechanical properties. Clinical study reported by Van Dijken have shown that restorative composite with microfibers suffer extensive wear [29], which can be partly explained because of the used fiber length was well below of critical fiber length. In order a fiber to act as an effective reinforcement for polymers, stress transfer from the polymer matrix to the fibers is essential [30,31]. This is achieved, if the fibers have a length equal or greater than the critical fiber length [30]. It has been measured using fiber fragmentation test that the critical fiber lengths of E-glass with bis-GMA polymer matrix vary between 0.5 and $1.6 \mathrm{~mm}$ [32]. Deteriorated or initially poor adhesion between the fibers and polymer matrix increase the critical fiber length. In this case, the

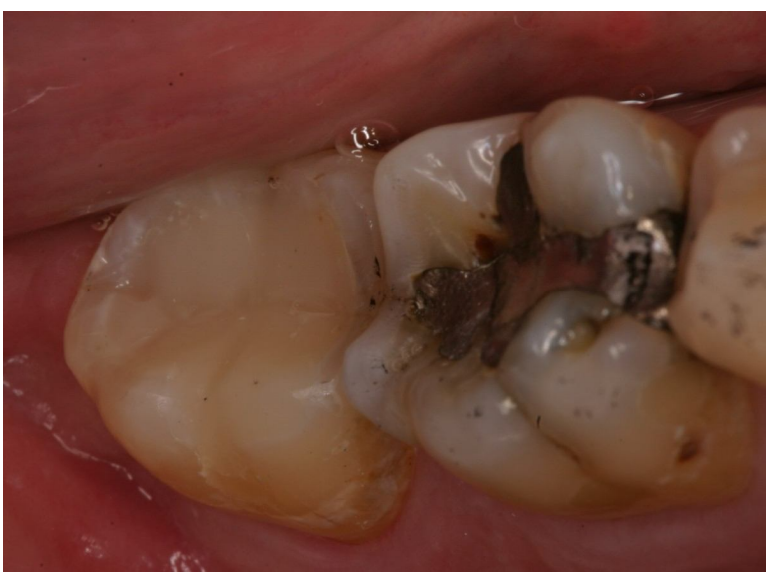

Fig. (4). The cavity is filled with restorative composites and the restoration is finished and adjusted in occlusion.

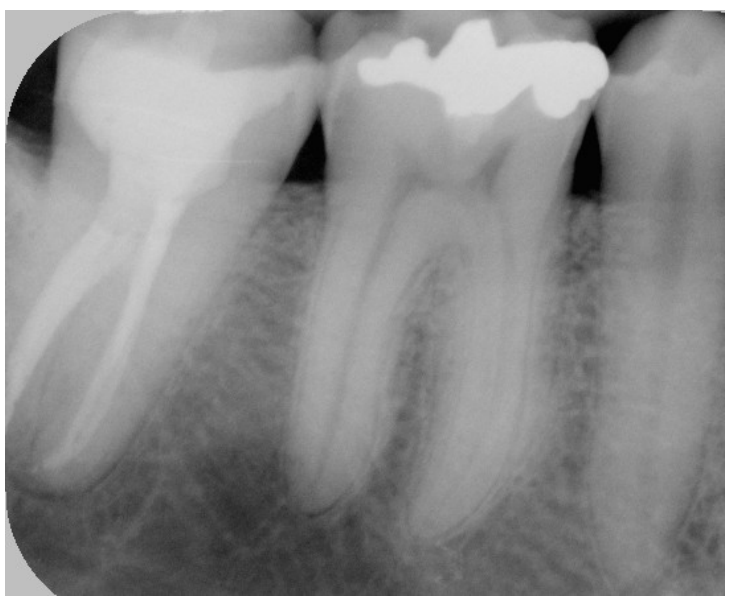

Fig. (5). An X-ray showing the finished restoration with materials combination of bulk short fiber composite substructure and surface layer of particulate filler composite.

mechanical friction of fibers to polymer matrix at the interface can compensate the poor adhesion [33]. Based on this, the short fiber composite resins used in this study have fiber fillers equal or greater to critical fiber length.

To receive support from the short fiber composite substructure for the surface particulate composite, the structural rigidity of the short fiber composite substructure should be higher than that of surface particulate composite resin.

In this, the fiber orientation likely has a significant role. On the other hand, if the function of the short fiber composite substructure is based on the mechanism of a crack stopper, the distance from the surface of the stress initiation point to the fibers is of importance. Therefore, the volume fraction or thickness of short fiber composite could contribute to the crack propagation and load-bearing capacity. Previous study by authors, showed when short random fiber-reinforced composite (FRC) was used as substructure for particulate filler composite, the load-bearing capacity of the materials combination increased linearly as thickness layer of FRC increased [16]. From this point of view, in this clinical report, short fiber composite-substructure was covered with only one layer of hybrid particulate filler composite in order to prevent fiber exposure. Although, bacterial adhesion (Streptococcus mutans) did not demonstrate difference to 
short fiber composite resin than to other restorative materials [34].

Stress applied to the teeth and restorations is generally repetitive or cyclic rather than being isolated and impact in nature. Regarding to this, materials combination of short fiber composite and particulate filler composite showed higher fatigue limit than that obtained with plain particulate filler composite [15].

Most of dentists participated in this multi-centered clinical trial used flowable composite as liner on cavity floors. Despite the popularity of the use of flowable composite on the bottom of cavity, there is only few clinical studies have investigated the effectiveness of this technique and compared with traditional direct placement of composite resin and these studies reported no significant differences between the techniques $[35,36]$.

Finally, it is necessary to emphasize that the time frame and cases for this clinical trial were not of such duration and number to indicate the long-term suitability of the tested materials combination, but it may provide an indication regarding their future performance in high stress bearing applications.

\section{CONCLUSIONS}

Within limitations of this pilot clinical report, the results showed good clinical performance of a novel materials combination of bulk short fiber composite substructure and surface layer of particulate filler composite in high stress bearing areas after 1 year.

\section{CONFLICT OF INTEREST}

None declared.

\section{ACKNOWLEDGEMENT}

None declared

\section{REFERENCES}

[1] Bowen RL. Properties of a silica-reinforced polymer for dental restorations. J Am Dent Assoc 1963; 66: 57-64.

[2] Wilder AD Jr, May KN Jr, Bayne SC, Taylor DF, Leinfelder KF. Seventeen-year clinical study of ultraviolet-cured posterior composite Class I and II restorations. J Esthet Dent 1999; 11:135-42.

[3] Opdam NJ, Loomans BA, Roeters FJ, Bronkhorst EM. Five-year clinical performance of posterior resin composite restorations placed by dental students. J Dent 2004; 32: 379-83.

[4] Roulet JF. Benefits and disadvantages of tooth-coloured alternatives to amalgam. J Dent 1997; 25: 459-73.

[5] Manhart J, Chen H, Hamm G, Hickel R. Buonocore Memorial Lecture. Review of the clinical survival of direct and indirect restorations in posterior teeth of the permanent dentition. Oper Dent 2004; 29: 481-508.

[6] Bayne SC, Thompson JY. Mechanical property analysis of two admixed PRIMM-modified commercial dental composites. Trans Acad Dent Mater 1996; 9: 238.

[7] $\mathrm{Xu} \mathrm{HH}$. Dental composite resins containing silica-fused ceramic single-crystalline whiskers with various filler levels. J Dent Res 1999; 78: 1304-11.

[8] Wilder AD Jr, Bayne SC, Heymann HO. Long-term clinical performance of direct posterior composites. Trans Acad Dent Mater 1996; 9: 151-69.

[9] Ferracane JL, Berge HX, Condon JR. In vitro aging of dental composites in water effect of degree of conversion, filler volume, and filler/matrix coupling. J Biomed Mater Res 1998; 42: 465-72.
[10] Asmussen E. Restorative resins: hardness and strength $v s$. quantity of remaining double bonds. Scand J Dent Res 1982; 90: 484-9.

[11] Eick JD, Kaufman GM, Chappelow CC. Applications of polymers: what are the future trend? Acad Dent Mater Trans 1979; 10: 89-98.

[12] Watts DC, Hindi AA. Intrinsic soft-start polymerization shrinkagekinetics in an acrylate-based resin composite. Dent Mater 1999; 15: 39-45.

[13] Krause WR, Park SH, Straup RA. Mechanical properties of BisGMA resin short glass fiber composites. J Biomed Mater Res 1998; 23: 1195-211.

[14] Petersen RC. Discontinuous fiber-reinforced composites above critical length. J Dent Res 2005; 84: 365-70.

[15] Garoushi S, Lassila LVJ, Tezvergil A, Vallittu PK. Static and fatigue compression test for particulate filler composite resin with fiber-reinforced composite substructure. Dent Mater 2007; 23: 1723.

[16] Garoushi S, Lassila LVJ, Tezvergil A, Vallittu PK. Load bearing capacity of fiber-reinforced and particulate filler composite resin combination. J Dent 2006; 34; 179-84.

[17] Xu HHK, Quinn JB, Smith DT, Giuseppetti AA, Eichmiller FC. Effect of different whiskers on the reinforcement of dental resin composites. Dent Mater 2003; 19: 359-67.

[18] Zandinejad AA, Atai M, Pahlevan A. The effect of ceramic and porous fillers on the mechanical properties of experimental dental composites. Dent Mater 2006; 22: 382-7.

[19] Loza-Herrero MA, Rueggeberg FA, Caughman WF, Schuster GS, Lefebvre CA, Gardner FM. Effect of heating delay on conversion and strength of a post-cured resin composite. J Dent Res 1998; 77: 426-31.

[20] Garoushi S, Vallittu PK, Lassila LVJ. Short glass fiber reinforced restorative composite resin with semi-interpenetrating polymer network matrix. Dent Mater 2007; 23: 1356-62.

[21] Garoushi S, Vallittu PK, Lassila LVJ. Direct restoration of severely damaged incisors using short fiber-reinforced composite resin. J Dent 2007; 35: 731-6.

[22] Garoushi S, Vallittu PK, Watts DC, Lassila LVJ. Polymerization shrinkage of experimental short glass fiber reinforced composite with semi-inter penetrating polymer network matrix. Dent Mater 2008; 24: 211-5.

[23] Garoushi S, Vallittu P, Lassila LVJ. Fracture toughness, compressive strength and load-bearing capacity of short glass fiberreinforced composite resin. Chin J Dent Res 2011; 14: 15-9.

[24] Norman RD, Wilson NHF. Three-year finidings of a multiclinical trail for a posterior composite. J Prosthet Dent 1988; 59: 577-83.

[25] Raskin A, Michotte-Theall B, Vreven J, Wilson NHF. Clinical evaluation of a posterior composite 10-year report. J Dent 1999; 27: 13-9.

[26] Garoushi S, Vallittu P, Lassila LVJ. Continuous and short fiber reinforced composite in root post-core system of severely damaged incisors. Open Dent J 2009; 18: 36-41.

[27] Garoushi S,Vallittu PK, Lassila LVJ. Fracture resistance of short random oriented glass fiber reinforced composite premolar crowns. Acta. Biomater 2007; 3: 779-84.

[28] Garoushi S,Vallittu PK, LassilaLVJ. Use of isotropic short fiber reinforced composite with semi-interpenterating polymer network matrix in fixed partial dentures. J Dent 2007; 35: 403-8.

[29] Van Dijken JWV, Grönberg KS. Fiber-reinforced packable resin composite in class II cavities. J Dent 2006; 34: 763-9.

[30] Petersen RC. Discontinuous fiber-reinforced composites above critical length. J Dent Res 2005; 84: 365-70.

[31] Vallittu PK, Lassila VP, Lappalainen R. Transverse strength and fatigue of denture acrylic-glass fiber composite. Dent Mater 1994; 10: $116-21$.

[32] Cheng TH, Jones FR, Wang D. Effect of fiber conditioning on the interfacial shear strength of glass-fiber composite. Compos Sci Technol 1993; 48: 89-96.

[33] Karacaer Ö, Polat TN, Tezvergil A, Lassila LVJ, Vallittu PK. The effect of length and concentration of glass fibers on the mechanical properties of an injection- and a compression-molded denture base polymer. J Prosthet Dent 2003; 90: 385-93.

[34] Lassila LVJ, Garoushi S, Tanner J, Vallittu PK, Söderling E. Adherence of Streptococcus mutans to fiber-reinforced filling composite and conventional restorative materials. Open Dent J 2009; 3: 227-32. 
[35] Ernts CP, Canbek K, Aksogan K, Willerhausen B. Two-year clinical performance of packable posterior composite with and without a flowable composite liner. Clin Oral Investig 2003; 7: 129-34.
[36] Van Dijken JWV, Pallesen U. Clinical performance of a hybrid resin composite with and without an intermediate layer of flowable resin composite: a 7 years evaluation. Dent Mater 2011; 27: 150-6.

Received: November 05, 2011

Revised: December 30, 2011

Accepted: December 30, 2011

(c) Garoushi et al.; Licensee Bentham Open.

This is an open access article licensed under the terms of the Creative Commons Attribution Non-Commercial License (http://creativecommons.org/licenses/by-nc/3.0/) which permits unrestricted, non-commercial use, distribution and reproduction in any medium, provided the work is properly cited. 